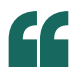

It took us a while to get our head around this but it is what makes bonding possible in the first place

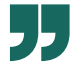

MAIN-GROUP CHEMISTRY

\section{Carbonyl trapped in silico}

When ligands bind to a transition metal its valence $d$ shell gets split, which has interesting consequences if the shell is partially filled. Here, the energy differences between frontier orbitals can be small enough to make the metal a good $\sigma$-acid and $\pi$-base - useful properties when it comes to binding substrates such as $\mathrm{H}_{2}$ and $\mathrm{CO}$. Chemists seek to replicate this behaviour using low-valent compounds of main-group elements, yet these species rarely have the appropriate atomic or electronic structure to afford stable adducts. A team led by Stephan Schulz and Peter Schreiner have hit back by preparing a silylene that enjoys steric and electronic protection in the form of bulky Ga-donor ligands. This privileged silylene, which the team now describes in

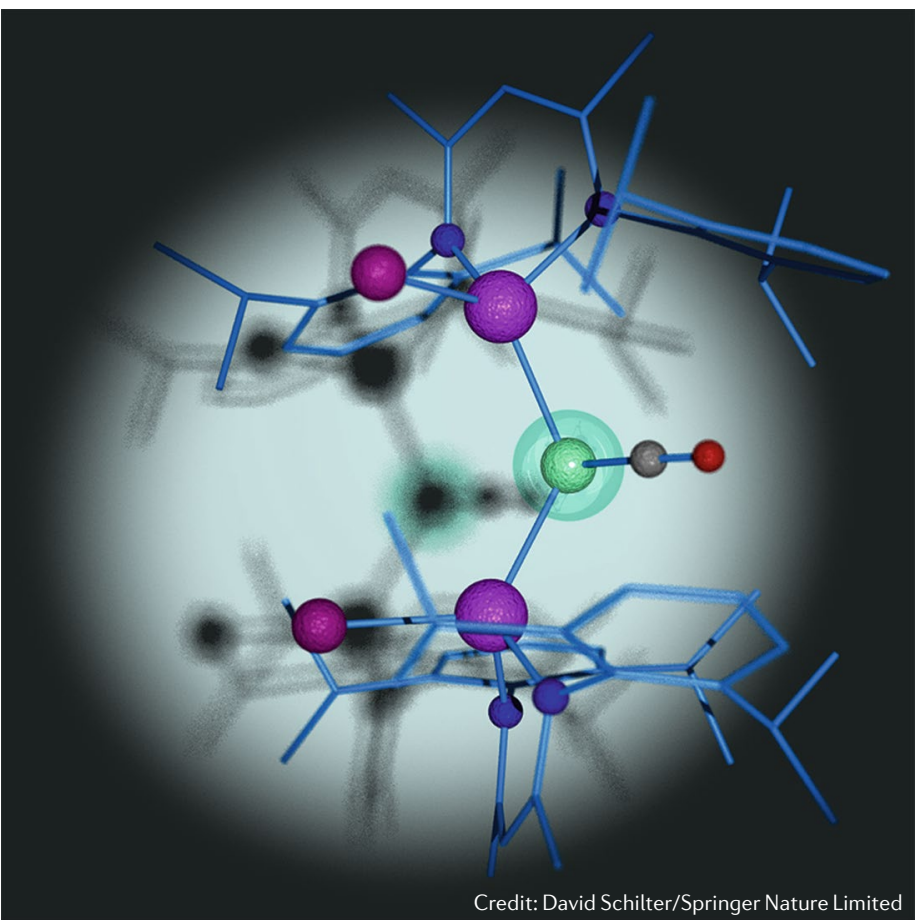

Nature Chemistry, is ideally set up to split $\mathrm{H}_{2}$ or form a rare complex with $\mathrm{CO}$.

Carbenes are likened to transition metals because $\mathrm{C}$ has two valence electrons to distribute between an $s p^{2}$ hybrid orbital and a higher-lying stabilize a carbene is to introduce $\pi$-donor substituents that increase the singlet-triplet energy gap, but this often robs the carbene of its ability to activate certain bonds. Enter the silylenes - divalent $\mathrm{Si}$ analogues of carbenes that exist as singlet species yet have distinct reactivity.

Early matrix-isolation work on the simplest silylene, $\mathrm{H}_{2} \mathrm{Si}$;, uncovered a non-planar $\mathrm{H}_{2} \mathrm{Si}$ :-CO complex in which Si plays the synergistic role of $\sigma$-acid and $\pi$-base reminiscent of transition metals. Schulz, Schreiner and their colleagues used density functional theory calculations to show that this complex is $16 \mathrm{kcal} \mathrm{mol}^{-1}$ lower in energy than the silaketene $\mathrm{H}_{2} \mathrm{Si}=\mathrm{CO}$. By contrast, $\mathrm{H}_{2} \mathrm{C}$ : has greater access to its triplet state, such that its singly occupied $s p^{2}$ and $p$ orbitals engage in typical $\sigma$ and $\pi$ covalent bonding with $\mathrm{CO}$ to give ketene $\mathrm{H}_{2} \mathrm{C}=\mathrm{CO}$, which now lies $6 \mathrm{kcal} \mathrm{mol}^{-1}$ lower than the non-planar isomer $\mathrm{H}_{2} \mathrm{C}$ :-CO.

Despite its fragility, the observation of $\mathrm{H}_{2} \mathrm{Si}$ :-CO inspired the team to prepare a more stable analogue so they could probe its bonding and chemistry. For this they turned to other main-group chemistry they had developed, namely insertion reactions of unsaturated Ga species LGa $\left(\mathrm{L}^{-}=N, N^{\prime}\right.$-bis (2,6-diisopropylphenyl)-1,3pentanediiminate). Thus, they converted $\mathrm{SiBr}_{4}$ to $[\mathrm{L}(\mathrm{Br}) \mathrm{Ga}]_{2} \mathrm{SiBr}_{2}$, a tetravalent species that undergoes $p$ orbital. A common strategy to debromination when treated with a further equivalent of LGa to generate a putative $[\mathrm{L}(\mathrm{Br}) \mathrm{Ga}]_{2} \mathrm{Si}$ i intermediate. If left to its own devices, the Si centre inserts into a $\mathrm{C}-\mathrm{C}$ bond of its own ligand, so Schulz, Schreiner and colleagues conducted debromination under $\mathrm{CO}$ in hopes of trapping it as a complex (when under $\mathrm{H}_{2}$ the reaction affords silane $\left.[\mathrm{L}(\mathrm{Br}) \mathrm{Ga}]_{2} \mathrm{SiH}_{2}\right)$. Gratifyingly, the team isolated $[\mathrm{L}(\mathrm{Br}) \mathrm{Ga}]_{2} \mathrm{Si}$ - $-\mathrm{CO}$ and its X-ray structure reveals a non-planar arrangement that enables $p_{\mathrm{Si}} \leftarrow s p_{\mathrm{C}}$ $\sigma$-bonding and synergistic $s p_{\mathrm{Si}_{\mathrm{i}}}^{2} \rightarrow \pi_{\mathrm{CO}}^{*}$ backbonding. But the same arrangement exists in $\mathrm{H}_{2} \mathrm{Si}$ :-CO, so why is $[\mathrm{L}(\mathrm{Br}) \mathrm{Ga}]_{2} \mathrm{Si}$--CO stable at room temperature? Calculations on $[\mathrm{L}(\mathrm{Br}) \mathrm{Ga}]_{2} \mathrm{Si}$ : indicate that the bulkiness of the $\mathrm{L}(\mathrm{Br}) \mathrm{Ga}$ groups brings them apart and raises the energy of the $s p_{\mathrm{Si}}^{2}$ lone pair, which is now a better $\pi$-donor. Conversely, overlap of vacant $p$ orbitals on the $\mathrm{Si}$ and $\mathrm{Ga}$ centres ensures that the $p_{\mathrm{Si}}$ orbital is a good $\sigma$-acceptor. Curiously, $\pi$-bonding dominates, so it is arguable if we can even call it 'backbonding. "It took us a while to get our head around this but it is what makes bonding possible in the first place," notes Schreiner.

Like many a metal carbonyl, $[\mathrm{L}(\mathrm{Br}) \mathrm{Ga}]_{2} \mathrm{Si}$ :-CO undergoes substitution with isonitrile CNCy to give $[\mathrm{L}(\mathrm{Br}) \mathrm{Ga}]_{2} \mathrm{Si}$ :-CNCy. "I am pretty sure that the mechanism is associative because it proceeds at $25^{\circ} \mathrm{C}$ while the precursor is stable to decarbonylation up to $80^{\circ} \mathrm{C}$," predicts Schulz. The team is now investigating ligand exchange and $\mathrm{Si}$-assisted reactions at the $\mathrm{CO}$ ligand itself. This chemistry is a hallmark of transition metals and will no doubt motivate more investigations into such fertile main-group systems.

David Schilter

ORIGINAL ARTICLE Ganesamoorthy, C. et al. A silicon-carbonyl complex stable at room temperature. Nat. Chem. https://doi.org/10.1038/ s41557-020-0456-x (2020) 